investigated this point also, and they appear to have found sun-spot inequalities depending on the relative positions of the various influential planets.

For instance, there is a greater than usual amount of sun-spots when Venus and Jupiter are together; there is the same a little before the time when either Venus and Mercury or Mercury and Jupiter are together, and finally, there is the same a little before the time when Mercury is nearest the sun.

These results of strictly solar observation are capable of being verified in quite a different manner. If the ylanets have an influence on the sun and if the state of the sun's surface affects terrestrial magnetism, it might be expected that we should have magnetic inequalities depending upon the positions of the planets.

By this it is not meant that the planets influence the magnetism of the earth directly, but rather through their effect upon the solar surface.

Again, it was shown in the last article that terrestrial magnetic effects at Kew lag behind corresponding states of the solar surface. This lagging behind ought therefore to be exhibited in any comparison which we make between sun-spot inequalities depending on the planets and magnetic inequalities at Kew depending on the same cause if the latter inequalilics are caused indirectly through the midium of the sum.

A comparison of this kind has recently been made by the writer, using for this purpose those inequalities of short period that were most likely to be exhibited in the limited series of magnetic observations at his disposal for the purpose.

The results are embodied in the preceding diagrams. Dirgram $D$ represents the sun spot, and diagram $F$, the mirnctic inequality aue to the relative positions of Mercury and Venus $\left(0^{\circ}\right.$ denoting conjunction). Diagram i represents the sun-spot, and diagram $G$ the magnetic inequality due to the varying distance of Mercury from the $\operatorname{sun}\left(\mathrm{O}^{\circ}\right.$ denoting perihelion). Diagram $\mathrm{H}$ represents the sun-spot, and diagram I the magnetic inequality due to the relative positions of Mercury and Jupiter $\left(\mathrm{O}^{\circ}\right.$ denoting conjunction). From all these it will be seen that there is a striking likeness in character between the planetary sun-spot inequalities, and the planetary magnetic inequalities derived from the records of the Kew Observatory - the latter, however, lagging behind the former in point of time, as might have been expected.

It is uncuestionably a very strange and striking conclusion that the daily range of the magnet freely suspended in a vault of the Kew Observatory, should be sensibly greater about the times when Venus and Mercury, or Venus and Jupiter come together in position, and also about the times when Mercury is nearest the sun,

Perhaps it is not too much to say that the facts described in the last article go to show that the sun influences the earth, and possibly also the other planets in some unaccountable manner, while the facts of this article go to show that (shall we say in return) the most conspicuous planets of the system, and possibly also the earth, are not without an influence upon the state of the solar surface. I may be permitted, in conclusion, to transcribe a paragraph from a former essay on this subject (Owens College essays). "At first sight we are startled by the supposition that a planet like Venus, which comes nearer to the earth than it ever does to the sun, should in any way be accountable for such enormous manifestations of energy as those which occur over the sun's surface. But the wonder will disappear if we bear in mind that there may be two kinds of causes or antecedents. Thus we may say that the blacksmith is the cause of the blow with which his hammer strikes the anvil, and here the strength of the blow depends upon the strength of the smith. But we may likewise say that the man who pulls the trigger of a gun or cannon is the cause of the motion of the ball, and here there is no relation between the strength of the effect and that of its cause.

"Now, in whatever mysterious way Venus and Mercury affect the sun, we may be sure it is not after the fashion of the blacksmith - they do not deal him a violent blow producing all this enormous effect, but they rather pull the trigger, and immediately a very great change takes place."

BALFOUR STEWART

(To be continued.)

\section{THE NEW ZOOLOGICAL GARDENS AT \\ CALCUTTA}

THE propriety of establishing Zoological Gardens at Calcutta, has, as those who are acquainted with the proceedings of the Asiatic Society of Bengal are well aware, been before the public and the Indian Government for these last fifty years. It is, however, only within a very recent period that anything has been practically effected, and the first report on the progress made in the development of the new institution cluring the first year of its existence has only just reached us. Before alluding to its contents, a few words on the origin of the present scheme may be acceptable to those who take an interest in the subject.

Many previous plans for the institution of Zoological Gardens in Calcutta, including that proposed by Sir Joseph Fayrer in 1867 , having come to nothing, Mr. L. Schwendler, of the Indian Telegraph Department, brought the subject again to the notice of the Council of the Asiatic Society in March, 1873. Mr. Schwendlex proposed that the necessary capital should be raised by subscription, but that the Government of Bengal should grant the site and give a contribution towards the annual expenditure. This scheme, although taken up with interest by the Asiatic and Agricultural Societies and supported by the press, would have ended, like its predecessors, in failure, had not the energy of Mr. Schwendler led him to adopt a different course of action. Having a fine private collection of living animals of his own, Mr. Schwendler was able to prove to the Viceroy of India (then Lord Northbrook), who honoured him with a visit, how easy it was to maintain such an establishment in a climate so well adapted to animal and vegetable life as that of Calcutta. Instead of the large and expensive houses necessary in these inclement climes simple sheds suffice as a protection for the animals against the weather, and the luxuriant vegetation is ever springing up to contribute to their shelter and retirement. In fact, if only space is provided, and sufficient fencing is put up, animals can be kept almost in the same state as in their native wilds, and buildings may be dispensed with. So practical was Mr. Schwendler's illustration of how easily zoological gardens might be established in Calcutta by showing his own grounds fitted up for the purpose, that the Viceroy was convinced at once, and quickly brought the excellent Lieutenant-Governor of Bengal to a similar state of mind. Having taken up the matter, Sir Richard Temple set to work at it with his usual energy, and by a minute of September 24, 1875, granted a large site for the purpose on the road leading from Surat Bridge to the Governor's official residence at Belvedere. Shortly afterwards an honorary managing committee was appointed, with Lord Ullick Browne as president; Mr. Schwendler and Dr. King and Mr. Watson as members, and Mr. C. Buckland, private secretary to the Lieutenant-Governor, as honorary secretary. The objects of the new institution, besides the general instruction and recreation of the community, were specified to be to facilitate scientific observations on the habits of animals, to encourage their acclimatisation, and generally to promote the science of zoology. Upon the starting of the new institution, Mr. Schwendler immediately hastened to present to it his whole collection of living animals, and the Governor-General 
promised to remove the Barrackpore menagerie to the new site as soon as the necessary preparations were made. All the native princes, nobility, and gentry subscribed liberally towards the proposed garaens-for instance, the Maharajah of Burdwan gave $3,000 l$. ; others followed this liberal example, and the greater part of the required capital of $30,000 \%$. was quickly raised. Such rapid progress was made that occasion was taken of the Prince of Wales's presence in Calcutta on December 27,1875 , to inaugurate the new institution. His Royal Highness expressed his gratification at the results already achieved, praised Mr. Schwendler for the public spirit he had displayed, and accepted the patronship of the gardens.

The Royal Zoological Gardens of Calcutta thus inaugurated were opened to the public for the first time on May 6 of last year. From that date up to the close of the year more than 50,000 persons had visited them, without including members and donors, and soldiers with their wives and children who have a free entrance. The buildings are, of course, yet far from complete, but amongst those finished are, as we are informed, many deer-padclocks, which are already well tenanted; a large and scveral smaller aviaries, also well filled; a large bearhouse in three compartments, and furnished with a large bath; two monkey-houses, and a very large pit fitted up for the residence of rhinoceroses. Within the gardens is also a large tank or lake, with two islands used for waterfowl, and a restaurant and keepers' dwellings have likewise been erected.

At the present time Mr. C. T. Buckland, C.S., is the presicient of the Association for the maintenance of the gardens, and Dr. J. Anderson and Mr. H. M. Tobin have the general superintendence and honorary care of them, the paid officials consisting of natives only. A European director was appointed in Janwary, 1876 , but the Government of Bengal were shortly afterwards siopped by the Suprene Government from cortributing to the expenses of the gardens, and his services had consequently to be dispensed with.

This change of front in the Supreme Government, who had virtually pledged themselves to assist in the scheme, and who have not yet redeemed their promise to transfer the Barrackpore menagerie to the new gardens, is a subject of not unnatural complaint on the part of the committee, who are now striving hard to have matters replaced upon their former footing. As the Indian Government keep up botanical gardens in Calcutta, and pay a scientific officer a liberal salary to superintend them, they would surely be fully justified in treating the Zoological Gardens in the same way, especially until the new institution is fairly set a-going. Living animals, as we all know, are far more attraclive to the general public than living plants, and there can be no question, we believe, that in Calcutta, as in London, zoological gardens are more popular than botanical. The public of Calcutta have come bravely down with a sum of 30,000 . to set the institution going, and will be greatly disappointed if the Government do not support them. A scientific director for the establishment is an absolute necessity, as it cannot be expected that Dr. Anderson and others who now manage it can continue their gratuitous services. Lord Northbrook is now earning his well-merited repose in this country, but looking to the countenance and favour that he has already shown to the Zoological Gardens at Calcutta, we cannot doubt that he will assist in the appeal that is, we understand, now being made to the authorities at home, to obtain permission from the Government of Bengal to continue the support which it gave at first. We may also fairly call upon Lord Salisbury, who has on many occasions shown his appreciation of scientific work, to devote a few minutes' attention to this subject. It is certain that no better step could be taken for the advancement of Zoological Science in India than the establishment of the Zoological Gardens of Calcutta on a firm footing. Like our Gardens in London they might easily be made a centre whence encouragement is diffused to zoological investigations of every kind. A well-selected director, appointed and paid by the Government, would at once place matters on a satisfactory foundation, and tend to bring together support to the Institution from every quarter, and we cannot doubt that the present obstruction will be removed by the Central Authority as soon as the real facts of the case are brough before them.

\section{OUR ASTRONOMICAL COLUMN}

Dovile-Strar Measures at Cincinnati.-In Nos, $z$ and 3 of the publications of the Cincinnati Observatory are two series of micrometrical measures of double-stars made with the II-inch Merz refractor. The first series includes measures by Prof. O. M. Mitchell at the old Observatory, confined, with few exceptions, to the stars of the great Dorpat Catalogue, and made in the years $1846-48$, a small number of which only had appeared in the Sidereal. Messenger. - The second series com. prises measures of objects situated for the most part beyond Struve's limit of south cleclination made in the years $1875-76$, and will probably be found the most useful of the two, observations of these southern stars being as yet in small number. Mír. Ormond Stone, the present director at Cincinnati, remarks that " no systematic survey of the southern heavens similar to that made by Struve of the northern heavens has ever been undertaken," and a large proportion of Sir John Herschel.'s doubles have never been properly measured micrometrically. The Cincinnati object-glass having been refigured by Alvan Clark during the last winter, the director purposes devoting the instrument to supplementing the labours of other astronomers by measuring double-stars between $15^{\circ}$ and $35^{\circ}$ of south declination; no doubt in the course of this work new binary systems will be detected.

Amongst the stars in the second of the above series, is $h$ 2036 , the duplicity of which wa; first remarked by Sir John Herschel with the 20 -feet reflector in sweep 307 (1830, Oct. 15), when the position was registered $53^{\circ} \mathrm{O}$, and the estimated distance was $2^{\prime \prime}$. The last Cincinnati measures give for 1876.78 , position $26^{\circ} \cdot 4$, distance $I^{\prime \prime} \cdot 64$, and Capt. Jacob's intervening measures at Poona and Madras, confirm the retrograde motion in the angle; indeed, he first pointed out the probable binary character of the star, and also suggested another noticeable feature, viz., the apparent variability of both components (Mem. R.A.S., vol, xxviii. p. 41). A comparison of the whole of the estimates of magnitude to 1876 , is certainly confirmatory of Capt. Jacob's suspicion. The stars have not been noted as differing more than half a magnitude, and generally have been considered of equal brightness, yet the estimations vary from $6 \%$ (Jacob 1857) to $9^{\circ}$ (Ormond Stone, 1875). The object is well within reach in this country, and deserves watching. It may be remarked that the N.P.D, given in Sir John Herschel's fifth series of measures with the 20 -feet reflector, is $I^{\circ}$ too small. By an observation in the Washington zones, the position for the beginning of the present year is in R.A. Ih. I $3 \mathrm{~m} .54^{\prime} 7 \mathrm{~s}$, N.P.D. $106^{\circ} 26^{\prime} 15^{\prime \prime}$.

Change of Colour in a URSEe Majoris. - Herr Weber continues his observations upon the colour of this star, a periodical change in which from intense fiery-red to yellow was first suspected by Dr. Klein of Cologne about fifteen years since. According to Herr Weber the change is from fiery-red to white or slightly yellowish white. The following are recent observed epochs of red light:-1876: September 5, October 10, November 14, December 21. 1877: January 16, March 23, whence an average period of thirty-three days is indicated. The star was white or nearly white, 1876 : October 28 , December 30. 1877: February 8 and March 13 . The star is said to remain red or reddish for a shorter time than it is seen white or yellowish white. See Astron. Nach., Nos, 2, I I and 2, I 27. 